\title{
Acceptance of a pandemic influenza vaccine: a systematic review of surveys of the general public
}

\author{
This article was published in the following Dove Press journal: \\ Infection and Drug Resistance \\ 19 October 2011 \\ Number of times this article has been viewed
}

\author{
Trang Nguyen ${ }^{1,2}$ \\ Kirsten Holdt Henningsen' \\ Jamie C Brehaut ${ }^{1,2}$ \\ Erica $\mathrm{Hoe}^{\prime}$ \\ Kumanan Wilson 1,3 \\ 'Clinical Epidemiology Program, \\ Ottawa Hospital Research Institute; \\ ${ }^{2}$ Epidemiology and Community \\ Medicine, University of Ottawa; \\ ${ }^{3}$ Department of Medicine, University \\ of Ottawa, Ottawa, Canada
}

\begin{abstract}
Introduction: The effectiveness of pandemic vaccine campaigns such as the H1N1 vaccine rollout is dependent on both the vaccines' effectiveness and the general public's willingness to be vaccinated. It is therefore critical to understand the factors that influence the decision of members of the public whether to get vaccinated with new, emergently released vaccines.

Methods: A systematic review of English language quantitative surveys was conducted to identify consistent predictors of the decision to accept or decline any (pre)pandemic vaccine, including the H1N1 influenza A vaccine. A total of ten studies were included in this review and all pertained to the $2009 \mathrm{H} 1 \mathrm{~N} 1$ influenza A pandemic. Respondents' willingness to receive a pandemic vaccine ranged from $8 \%-67 \%$ across the ten studies. The factors reported to be consistent predictors of the intention to vaccinate were: risk of infection, proximity or severity of the public health event, severity of personal consequences resulting from the illness, harm or adverse events from the vaccine, acceptance of previous vaccination, and ethnicity. Age and sex were the demographic variables examined most frequently across the ten studies and there was no consistent association between these variables and the intention to accept or reject a pandemic vaccine.
\end{abstract}

Conclusion: Some predictors of the intention to accept or decline a (pre)pandemic vaccine or the H1N1 influenza A vaccine are consistently identified by surveys. Understanding the important factors influencing the acceptance of a pandemic vaccine by individual members of the public may help inform strategies to improve vaccine uptake during future pandemics.

Keywords: pandemic, H1N1 influenza A, emergent vaccine, personal risk, demographic

\section{Introduction}

The release of a pandemic vaccine to protect individuals from H1N1 was an unprecedented undertaking for many nations across the world. The development-to-implementation process of a new, emergency-released vaccine like the $\mathrm{H} 1 \mathrm{~N} 1$ vaccine differs in many ways from that of established vaccines, such as the seasonal influenza vaccine. Given the urgent need for a vaccine during the H1N1 pandemic or similar emergency situations, a vaccine must be developed and distributed in an efficient and timely manner to reduce the overall public health burden of the disease. Furthermore, a large portion of the population must be vaccinated within a short period to maximize the benefits of the vaccine. Vaccination campaigns that are successful in encouraging the general public to get vaccinated can help reduce the morbidity and mortality related to the emerging disease. Understanding the factors that influence decisions made by individual members of the public to accept or decline an emergency-released 
vaccine such as the H1N1 vaccine can help public health officials in preparedness planning and management activities for future infectious disease outbreaks.

Several surveys have examined the factors that influenced the uptake of the $\mathrm{H} 1 \mathrm{~N} 1$ vaccine. A systematic review of the published survey literature was conducted to synthesize the data from these studies and identify barriers and facilitators to vaccination that were consistently identified across studies.

\section{Methods}

\section{Search strategy}

A systematic search of the literature for all articles was conducted on July 26, 2010 using the MEDLINE (Ovid interface: January 1950 to July 26, 2010), EMBASE (Ovid interface: 1947 to July 26, 2010), and PsycINFO (Ovid interface: 1806 to July 26, 2010) databases. The search strategy for the MEDLINE database was based on medical subject headings and keywords. The research librarian ensured that the coding was as inclusive and exhaustive as possible and provided guidance in transporting the search strategy into other databases. The search strategy combined terms that represented attitudes, perceptions, and barriers and facilitators with "H1N1 influenza" and "pandemic vaccine." The searches were supplemented by a review of the references of key articles on the topic. The full search strategies are presented in the Appendix.

\section{Study selection}

All abstracts generated by the searches were added to a database and duplicates were removed prior to screening. Two reviewers independently screened the abstracts for eligibility. Agreement between reviewers on the selection of studies was compared using a Kappa score. All English articles that met the following criteria were included in the final meta-synthesis: sampled the general public and not a specific population; examined H1N1 pandemic, or swine flu, or other prepandemic vaccines and vaccination/ immunization; examined personal intention or willingness to get vaccinated, or actual vaccination rate, or barriers and/or predictors of intention to personally receive or having received the vaccination; obtained data through a quantitative survey.

Any disagreement between the reviewers was discussed and resolved by consensus. In cases where consensus was not achieved, a third reviewer addressed any discrepancies that arose.

\section{Data abstraction}

Two reviewers independently extracted data from the eligible studies and a third addressed any discrepancies that arose. From a preliminary review of the articles, the two reviewers developed a coding template, using the constant comparative method. ${ }^{1}$ The factors influencing vaccine use identified in the studies were categorized using this coding template, which consisted of broad headings termed "themes," and subheadings termed "categories." 2 The reviewers conducted a second review of the articles to extract quantitative survey data pertaining to the themes in the coding template. The quantitative data extracted from the studies had to meet one of the following criteria of significance; either: odds ratio (OR) values with a $P$-value of $<0.05$, or when a $P$-value is not provided the $95 \%$ confidence interval must not include the value of 1 , or the factors were indicated by the author(s) of the study to be statistically significant. If both univariate and multivariate analyses were available, data from the multivariate analyses were preferentially extracted. When the data were presented as percentage values, the top three responses for a given question were reported. The authors of all the studies included in the analysis were emailed and requested to review the information that was extracted to help ensure that the data extracted represented the data and results presented in the authors' respective publications.

\section{Statistical analysis}

Kappa scores were calculated to determine chance-adjusted interobserver agreement in the abstract and study selection processes. Due to the heterogeneity of the populations and survey methods covered by the studies included in the review, as well as a lack of guidelines on combining survey data, a meta-analysis was not conducted.

\section{Results \\ Study selection and characteristics}

The search strategy yielded 720 abstracts and titles (Figure 1). Of these, 51studies met selection criteria and the full articles were pulled for further analysis. A total of ten studies met the final inclusion criteria and were included in the systematic review. There was excellent agreement between the two reviewers for the initial screening of the abstracts $(\kappa=0.97)$ and the final articles $(\kappa=1.00)$.

The characteristics of the studies included in the review are summarized in Table 1 . The studies included in the analysis surveyed the general population of adults aged $\geq 18$ years, except for one study that surveyed participants 


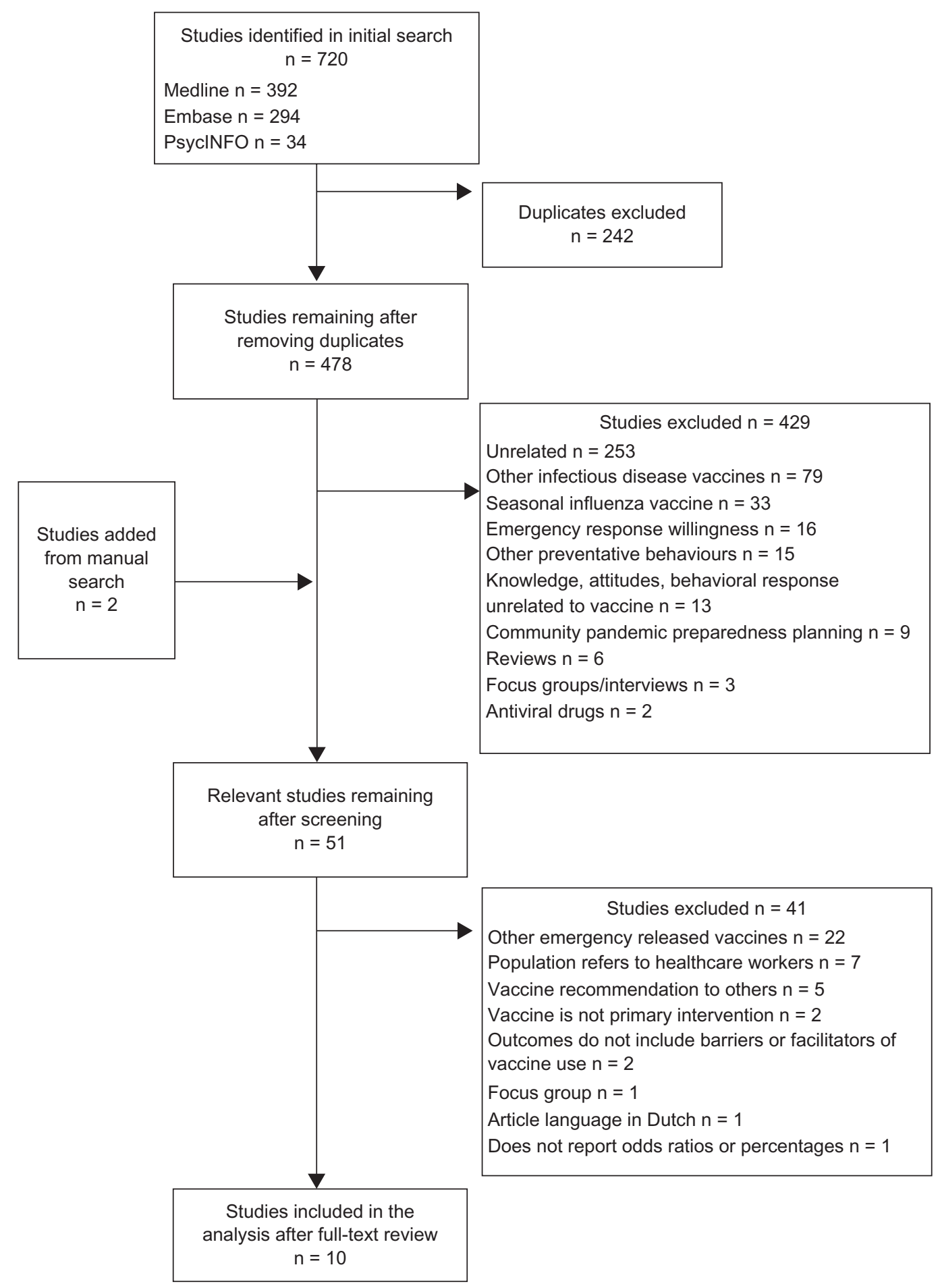

Figure I Flow diagram of selection of studies for the systematic review.

aged $\geq 16$ years. $^{3}$ The methods of survey administration included telephone surveys $(n=4)$, online surveys $(n=3)$, paper-based surveys $(n=2)$, and one survey was conducted in person. Five of the surveys were self-administered. ${ }^{4-8}$ The sample size of the ten studies ranged from $207^{9}$ to $5175^{3}$ respondents. The response rate for the surveys ranged from
$8 \%{ }^{3}$ to $80 \% .^{9}$ Three studies were conducted in the USA, ${ }^{4,5,9}$ four were conducted in Europe, ${ }^{3,6,8,10}$ two studies took place in Australia, ${ }^{7,11}$ and one in Hong Kong. ${ }^{12}$ All of the studies took place during the H1N1 influenza A pandemic. Five of these surveys were administered before the availability of the H1N1 vaccine in the respective countries. ${ }^{3,5,7,9,12}$ 


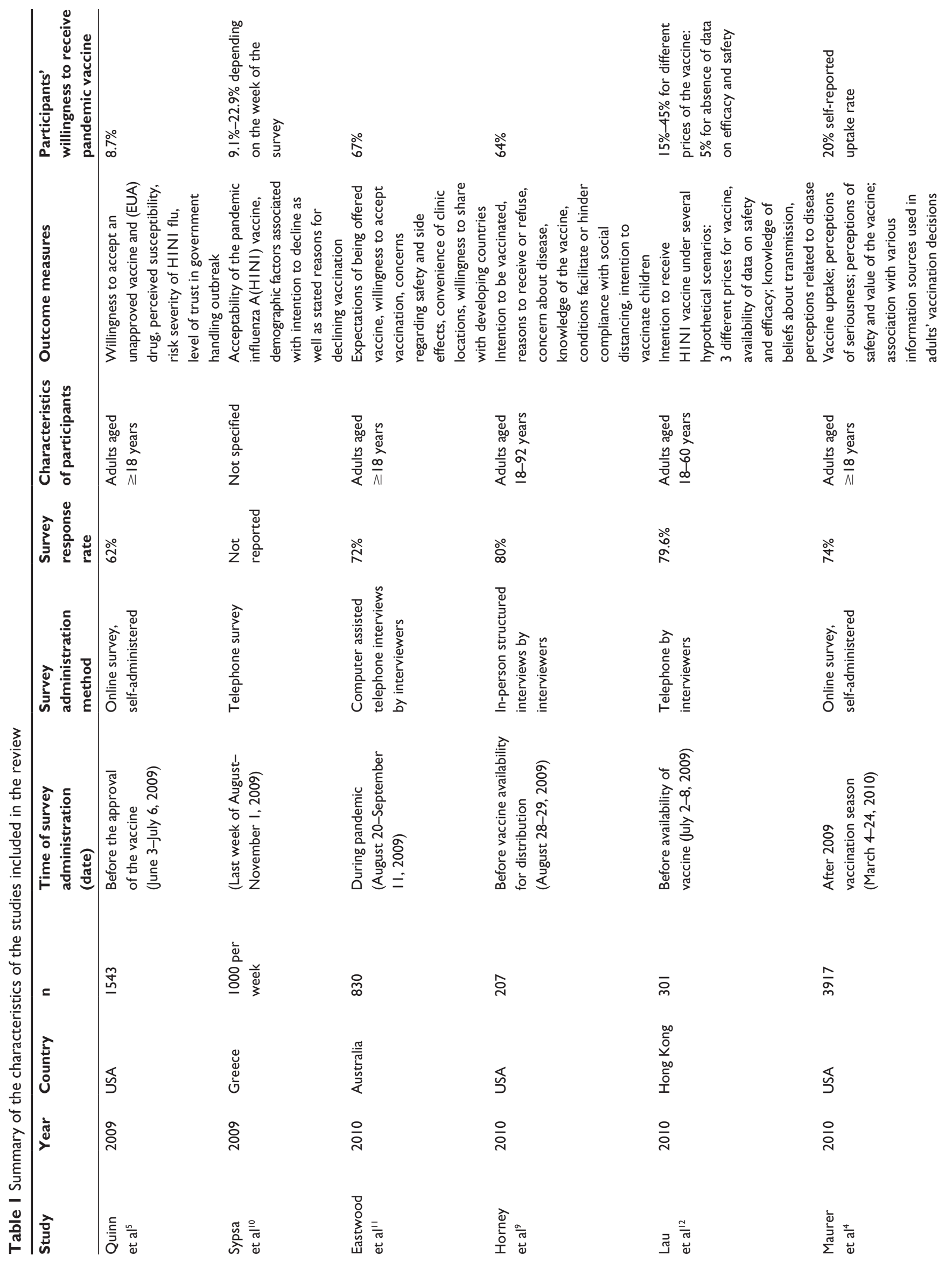




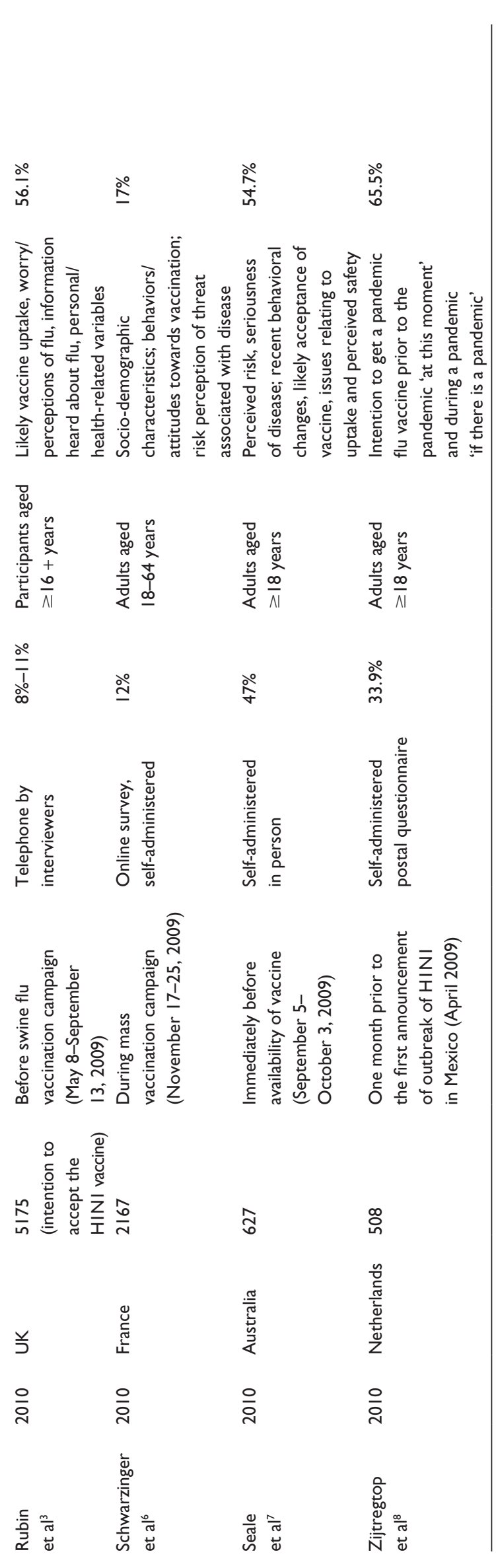

\section{Intention to vaccinate}

The reported willingness of the respondents to receive the pandemic vaccine was evaluated in nine studies and this ranged from $8 \%{ }^{5}$ to $67 \% .{ }^{11} \mathrm{~A}$ study conducted by Maurer and colleagues was conducted after the vaccination campaign and reported an actual vaccination rate of $20 \%$ for H1N1 influenza A vaccine in their study population. ${ }^{4}$

\section{Factors influencing intention to receive vaccination}

Table 2 reports the factors identified in the studies that influenced intention or willingness to receive a pandemic vaccine. The factors were categorized under the following themes: personal risk perception, vaccination attitude, communications and information sources, access, demographic variables, and others. The major themes summarized factors that share similarities and these themes are further divided into categories within each theme.

\section{Personal risk perception}

Nine studies were identified to report data under the theme personal risk perception. ${ }^{3,5-12}$ Of these, data on the perception of harm or adverse events from the vaccine were reported in seven studies..$^{5-7,9-12}$ Two of the seven studies ${ }^{5,12}$ reported ORs of $0.11,0.33$, and 0.36 , demonstrating that these concerns were associated with a lower intention to be vaccinated. Among the factors with the largest effect size for the intention to vaccinate was the perception of harm or adverse events from vaccine; in one study, participants who were more worried about the vaccine were $90 \%$ less likely to accept the vaccine $(\mathrm{OR}=0.11) .{ }^{5}$ Five studies reported the perception of harm or adverse events from the vaccine as one of the top three factors influencing the decision to accept or decline the new vaccine. . $, 7,9-11$ Four studies presented data on factors relating to the perception of the proximity or severity of the public health issues and reported ORs ranging from 1.2 to 2.5 , suggesting that this factor increased the intention to vaccinate. ${ }^{3,6,7,11}$ Four studies presented data on the perception of the severity of personal consequences from the illness and reported ORs ranging from 1.64 to $3.61 .5,6,8,9$ Five studies reported data pertaining to perceptions of the risk of infection with ORs ranging from 1.55 to $4.7 .^{3,7-10}$ In one study, participants who had higher levels of worry about personally catching the pandemic flu were almost five times more likely to accept the vaccine $(\mathrm{OR}=4.7) .^{3}$ 


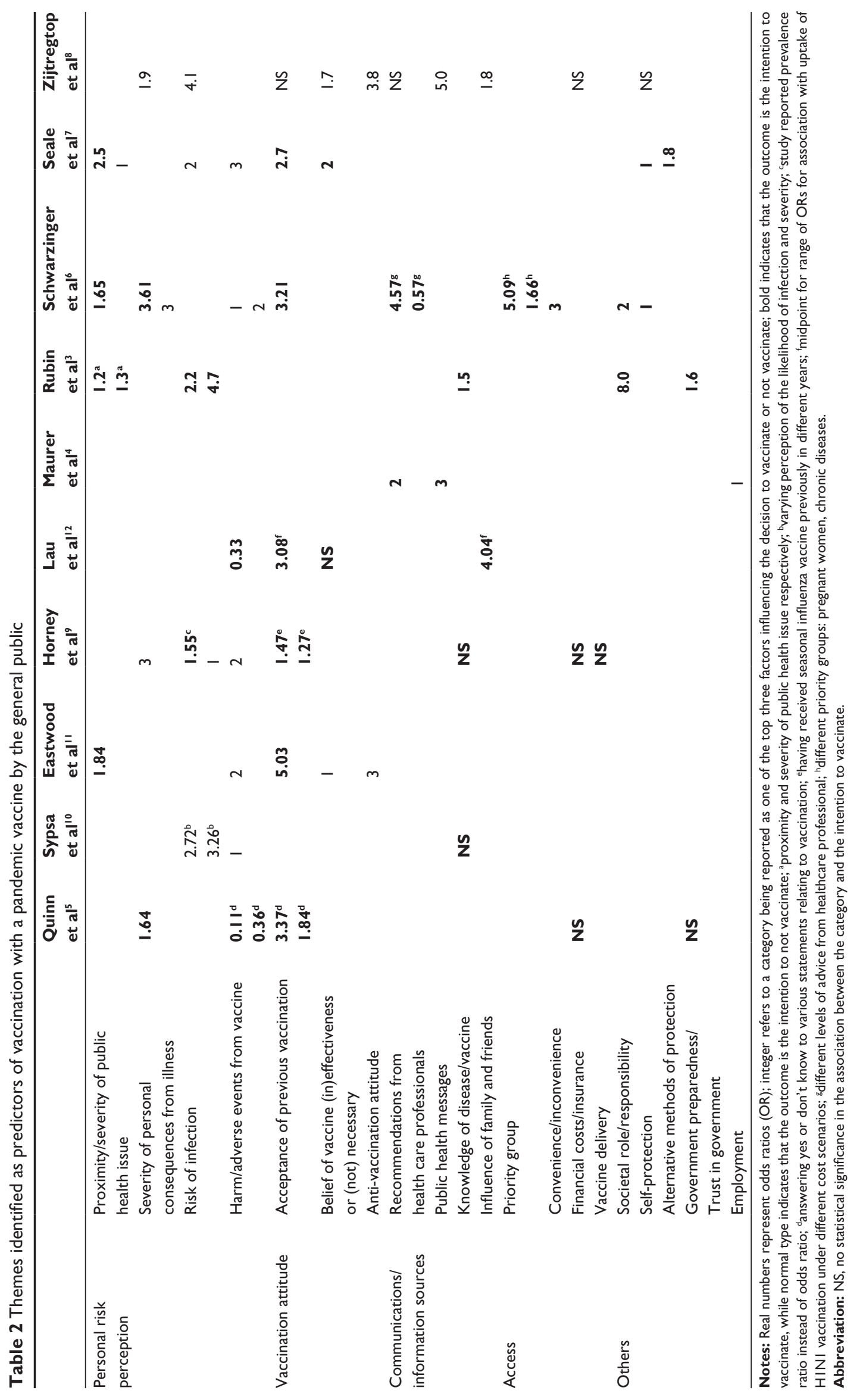




\section{Vaccination attitude}

Seven studies were identified to report data under the theme of

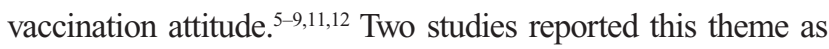
one of the top three factors influencing the decision to accept or decline the new vaccine. ${ }^{7,11}$ Data relating to people's acceptance of previous vaccination on their intention to vaccinate was reported by seven studies ${ }^{5-9,11,12}$ and six of these studies reported ORs ranging from 1.27 to 5.03, suggesting that this factor increased the intention to vaccinate..$^{5-7,9,11,12}$ Acceptance of previous vaccination was the factor with the largest effect on the intention to vaccinate, with those who accepted previous influenza vaccination shown to be five times more likely to accept a pandemic vaccine $(\mathrm{OR}=5.03)$ in one study. ${ }^{11}$ Information on people's belief of vaccine effectiveness or necessity and antivaccination attitude were less consistently reported and only four studies reported data on these two categories. ${ }^{7,8,11,12}$

\section{Communications and information sources}

Seven studies were identified to report data under the theme of communications and information sources. ${ }^{3,4,6,8-10,12}$ Within this larger theme the following categories were identified: recommendations from healthcare professionals, public health messages, knowledge of the disease or vaccine, and influence of family and friends. These categories were less consistently reported, with less than three studies reporting on each of the categories. Three of the seven studies reported nonsignificant association between this theme and the intention to vaccinate. ${ }^{8-10}$ In one study, recommendations from health care professionals had a large effect on the intention to vaccinate based on the different levels of advice given by health care professionals. Respondents who received positive advice from a primary care physician for vaccination were more likely to accept the pandemic vaccine $(\mathrm{OR}=4.57)$, and those who did not receive positive advice were more likely to decline the vaccine $(\mathrm{OR}=0.57){ }^{6}$

\section{Access}

Four studies were identified to report data under the theme of access. ${ }^{5,6,8,9}$ Within this broad theme the following categories were identified: priority group, convenience, financial costs/ insurance, and vaccine delivery. Three of the four studies reported nonsignificant association between access and the intention to accept a pandemic vaccine..$^{5,8,9}$ One study reported an odds ratio of 5.09 for acceptance of a pandemic vaccine for those in a priority group compared to those who were not. ${ }^{6}$

\section{Demographic variables}

The association between demographic variables and intention to accept or decline a pandemic vaccine are summarized in Table 3. Seven of ten studies reported data on the association between age and the intention to accept a pandemic vaccine. ${ }^{3,6,7,9-12}$ The association was not significant in three of the seven studies. . $^{7,9,12}$ Furthermore, there was inconsistency about which age group is more likely to accept a pandemic vaccine for studies reporting significant associations. Eight studies reported on the association between sex and the intention to accept a pandemic vaccine, which was shown to be not significant in five $3,7-9,12$ of the eight studies. ${ }^{3,6-12}$ Four studies reported on the association

Table 3 Demographic variables identified as predictors of vaccination with a pandemic vaccine by the general public

\begin{tabular}{|c|c|c|c|c|c|c|c|c|c|c|}
\hline & $\begin{array}{l}\text { Quinn } \\
\text { et al }{ }^{5}\end{array}$ & $\begin{array}{l}\text { Sypsa } \\
\text { et } \text { al }^{10}\end{array}$ & $\begin{array}{l}\text { Eastwood } \\
\text { et al"1 }\end{array}$ & $\begin{array}{l}\text { Horney } \\
\text { et al }{ }^{9}\end{array}$ & $\begin{array}{l}\text { Lau } \\
\text { et } \mathrm{al}^{12}\end{array}$ & $\begin{array}{l}\text { Maurer } \\
\text { et } \mathrm{al}^{4}\end{array}$ & $\begin{array}{l}\text { Rubin } \\
\text { et } \mathbf{a l}^{3}\end{array}$ & $\begin{array}{l}\text { Schwarzinger } \\
\text { et } \mathrm{al}^{6}\end{array}$ & $\begin{array}{l}\text { Seale } \\
\text { et } \mathrm{al}^{7}\end{array}$ & $\begin{array}{l}\text { Zijtregtop } \\
\text { et } \mathrm{al}^{8}\end{array}$ \\
\hline \multirow[t]{2}{*}{ Age } & & $1.85^{\mathrm{a}}$ & $1.64^{b}$ & NS & NS & & $1.6^{\mathrm{b}}$ & $1.4 I^{a}$ & NS & \\
\hline & & & & & & & & $2.1 I^{a}$ & & \\
\hline Sex & & $2.75^{c}$ & $1.86^{\mathrm{d}}$ & NS & NS & & NS & $0.57^{c}$ & NS & NS \\
\hline Ethnicity & $3.27^{e}$ & & & NS & & & $1.9^{e}$ & & $1.6^{\mathrm{e}}$ & \\
\hline Education & $0.40^{f}$ & NS & & & & & & $0.53^{g}$ & & NS \\
\hline Community/household- & & $1.60^{\mathrm{h}}$ & & NS & & & $2 . I^{h}$ & $1.68^{\mathrm{h}}$ & & NS \\
\hline \multirow[t]{2}{*}{ related factors } & & $1.56^{i}$ & & & & & NS & $0.6 \mathrm{I}^{\mathrm{i}}$ & & \\
\hline & & NS & & & & & & & & \\
\hline \multirow[t]{2}{*}{ Personal health } & 0.41 & & & & & & $1.5^{j}$ & NS & & \\
\hline & & & & & & & $1.4^{j}$ & & & \\
\hline Occupation/social & & & & NS & NS & & NS & $1.49-2.18^{k}$ & & \\
\hline \multicolumn{11}{|l|}{ grade/work status } \\
\hline Marital status & & & & & NS & & & & & \\
\hline
\end{tabular}

Notes: Real numbers represent odds ratios; bold indicates that the outcome is the intention to vaccinate, while normal type indicates that the outcome is the intention to not vaccinate; ${ }^{a}$ older age groups compared to younger age group ( $\leq 34$ years old); byounger age groups compared to older age group ( $60+$ years old); 'reference is men; ${ }^{d}$ reference is women; 'other ethnic backgrounds compared to white/caucasian; fhigher levels of education compared to high school level of education; glower levels of education compared to university education; 'physical household related variable; 'physical community related variable; 'different statements about one's health; 'variety of occupations compared to clerical.

Abbreviation: NS, no statistical significance in the association between the category with the intention to vaccinate or not vaccinate. 
between ethnicity and the intention to accept a pandemic vaccine. ${ }^{3,5,7,9}$ The reported ORs ranged from 1.6 to 3.27 for a higher intention to accept a pandemic vaccine in people who were not of Caucasian background, in countries composed of a heterogeneous mix of ethnic groups. ${ }^{3,5,7}$ Other demographic variables included education, community/household-related factors, personal health, occupation/social grade/work status, and marital status. For all of these, there was no clear trend toward statistical significance.

\section{Discussion}

In a public health emergency, promoting the uptake of an emergency-released vaccine by the target population can be a difficult challenge for public health authorities. If such a challenge is not properly addressed, it may impede efforts to manage the infectious disease. Determining the factors influencing the intention to accept or decline a pandemic vaccine may inform strategies to promote vaccination uptake in case of future public health emergencies. Specific strategies to address factors influencing the public's reluctance to be vaccinated with a pandemic vaccine may increase the rate of overall vaccine uptake and help public health authorities better manage the emerging public health concern.

This study systematically reviewed the existing survey literature on factors influencing the intention to accept or decline a pandemic vaccine. The findings of a survey are generally limited to the population from which they were obtained. However, if multiple surveys in several different geographical regions sampling different populations consistently identify similar findings, then the generalizability of the findings is increased.

Based on the findings of this review, issues relating to personal risk perceptions, including severity of the public health issue, risk of being infected by the virus, risk of severe illness from being infected, and risk of harm from a pandemic vaccine, are important factors that should be considered for future emergency vaccination campaigns. Developing strategies to modify people's perception of their own risk may help encourage members of the general public to obtain vaccinations during public health emergencies. The findings also suggest that targeted messaging should perhaps be used for individuals of different ethnic groups in countries with a heterogeneous mix of ethnic groups, such as Canada and the USA, to reach groups that are more reluctant to accept a pandemic vaccine during a public health emergency.

Studies that did not meet the inclusion criteria but examined similar constructs, identified similar findings. A study conducted in 1976 by Cummings and colleagues ${ }^{13}$ reported factors that played a significant role in explaining variance in the behavioral intention to vaccinate; these were: perceived susceptibility and perceived severity of the disease, perceived efficacy of vaccination, and physician's recommendation. Together, these factors accounted for $37.8 \%$ of the variance in the behavioral intention to vaccinate. Levine and colleagues ${ }^{14}$ also reported perceived risk as an independent facilitator of the likelihood to vaccinate. While addressing a previous influenza pandemic threat, these findings are consistent with the observations of this review. The findings from this review are also consistent with studies using other research methodologies. Focus groups conducted by Henrich and colleagues ${ }^{15}$ reported perception of risk of infection, severity of morbidity from infection, proximity and ease of spread of the disease, and concerns about the safety of the new vaccine, as being among the factors influencing the decision to vaccinate with a novel vaccine during a pandemic. A meta-analysis of the relationship between risk perception and vaccination behavior found strong evidence that perceived risk of getting the disease, perceived self-susceptibility to the disease, and perceived severity of consequences significantly predicted vaccination. ${ }^{16}$ In their review, Bish and collegues ${ }^{17}$ also reported perceived susceptibility to the disease and perceived severity of the disease as important predictors of protective behaviors, such as vaccination, during a pandemic.

The present review has important limitations. The review is specific but not sensitive for identifying generalizable themes. If a theme is not reported to be a consistent predictor of vaccination intention it may be a consequence of surveys not asking a specific question related to the theme, or not reporting data related to the theme. It is also limited by the biases inherent in the original studies, including response bias and social desirability bias. The responses the individuals gave of their intention to get vaccinated may not be a true indication of how they would behave in an actual pandemic, as intention does not consistently translate to behavior. Further research exploring the factors that influenced the vaccination behavior during the H1N1 pandemic is necessary for a complete understanding of the behavior pre- and postpandemic. Further, the results presented are also not generalizable to non-English-speaking populations. Non-English-language papers were specifically excluded because translation could result in distortion of meaning of themes and subsequent misclassification. Another limitation resulting from the exclusion of non-Englishlanguage papers is the possibility of reporting biases that may occur as statistically significant (positive) studies are more likely to be submitted and accepted for publication and are more likely to be published in English. ${ }^{18}$ 


\section{Conclusion}

This review suggests that across different populations, the factors consistently associated with intention to accept or decline a pandemic vaccine include personal risk perception, vaccination attitude, and ethnicity. In future, emergency vaccination campaigns' public health officials should be cognizant of these issues in hope of increasing acceptance of a pandemic vaccine by the general public. In particular, the components of personal risk perception and vaccination attitude represent potentially modifiable factors that officials could develop strategies to influence, prior to and during the release of an emergent vaccine. By addressing these factors proactively public health officials may increase the uptake of an emergently released vaccine and reduce the overall impact of the emerging disease.

\section{Disclosure and acknowledgments}

The authors would like to thank Alexandra Davis for her guidance in developing the search strategies. Kumanan Wilson is supported by the Canadian Institutes of Health Research (CIHR) through the CIHR operating grant Health Systems, Ethics, and Knowledge Translation Research on Implications of H1N1 (grant number H1N - 104059). Trang Nguyen received funding from the Frederick Banting and Charles Best Canada Graduate Scholarship from CIHR in 2010. The funders had no role in study design, data collection and analysis, decisions to publish, or preparation of the manuscript. No other conflicts of interest are reported by the authors.

\section{References}

1. Jupp V. The Sage Dictionary of Social Research Methods. London: Sage Publications; 2006.

2. Mills E, Jadad AR, Ross C, Wilson K. Systematic review of qualitative studies exploring parental beliefs and attitudes toward childhood vaccination identifies common barriers to vaccination. J Clin Epidemiol. 2005;58(11):1081-1088.

3. Rubin GJ, Potts HW, Michie S. The impact of communications about swine flu (influenza A H1N1v) on public responses to the outbreak: results from 36 national telephone surveys in the UK. Health Technol Assess (Winchester, England). 2010;14(34):183-266.
4. Maurer J, Uscher-Pines L, Harris KM. Perceived seriousness of seasonal and $\mathrm{A}(\mathrm{H} 1 \mathrm{~N} 1)$ influenzas, attitudes toward vaccination, and vaccine uptake among US adults: does the source of information matter? Prev Med. 2010;51(2):185-187.

5. Quinn SC, Kumar S, Freimuth VS, Kidwell K, Musa D. Public willingness to take a vaccine or drug under Emergency Use Authorization during the 2009 H1N1 pandemic. Biosecur Bioterror. 2009;7(3):275-290.

6. Schwarzinger M, Flicoteaux R, Cortarenoda S, Obadia Y, Moatti JP. Low acceptability of A/H1N1 pandemic vaccination in French adult population: did public health policy fuel public dissonance? PLoS One. 2010;5(4): e10199.

7. Seale H, Heywood AE, McLaws ML, et al. Why do I need it? I am not at risk! Public perceptions towards the pandemic (H1N1) 2009 vaccine. BMC Infect Dis. 2010;10:99.

8. Zijtregtop EA, Wilschut J, Koelma N, et al. Which factors are important in adults' uptake of a (pre)pandemic influenza vaccine? Vaccine. 2009; 28:207-227.

9. Horney JA, Moore Z, Davis M, MacDonald PD. Intent to receive pandemic influenza A (H1N1) vaccine, compliance with social distancing and sources of information in NC, 2009. PLoS One. 2010;5(6): e11226.

10. Sypsa V, Livanios T, Psichogiou M, et al. Public perceptions in relation to intention to receive pandemic influenza vaccination in a random population sample: evidence from a cross-sectional telephone survey. Euro Surveill. 2009;14(49):pii. 19437.

11. Eastwood K, Durrheim DN, Jones A, Butler M. Acceptance of pandemic (H1N1) 2009 influenza vaccination by the Australian public. Med $J$ Aust. 2010;192:33-36.

12. Lau JT, Yeung NC, Choi KC, Cheng MY, Tsui HY, Griffiths S. Factors in association with acceptability of A/H1N1 vaccination during the influenza A/H1N1 pandemic phase in the Hong Kong general population. Vaccine. 2010;28(29):4632-4637.

13. Cummings KM, Jette AM, Brock BM, Haefner DP. Psychosocial determinants of immunization behaviour in a swine influenza campaign. Med Care. 1979;17(6):639-649.

14. Levine AJ, Trent RB. The swine flu immunization program: a comparison of inoculation recipients and nonrecipients. Eval Health Prof. 1978;1:195-215.

15. Henrich N, Holmes B. The public's acceptance of novel vaccines during a pandemic: A focus group study and its application to influenza H1N1. Emerg Health Threats J. 2009;2:e8.

16. Brewer NT, Chapman GB, Gibbons FX, Gerrard M, McCaul KD, Weinstein ND. Meta-analysis of the relationship between risk perception and health behavior: the example of vaccination. Health Psychol. 2007;26:136-145.

17. Bish A, Michie S. Demographic and attitudinal determinants of protective behaviours during a pandemic: a review. Br J Health Psychol. 2010;15:797-824.

18. Pai M, McCulloch M, Gorman JD, et al. Systematic reviews and meta-analyses: an illustrated, step-by-step guide. Natl Med J India. 2004;17(2):86-95 


\section{Appendix}

\section{Search strategies}

Database: Ovid MEDLINE ${ }^{\circledR}$ in-process

and other nonindexed citations

and Ovid MEDLINE ${ }^{\circledR} 1950$ to present

\section{Search strategy}

1 Vaccination/or Mass Vaccination/or vaccin\$.tw. (181200)

2 Anthrax Vaccines/or Smallpox Vaccine/or Influenza Vaccines/or (H1N1 or swine flu or H5N1 or avian flu or bird flu).tw. (21236)

31 or 2 (189137)

4 Disease Outbreaks/or (pandemic\$ or epidemic\$ or outbreak\$).tw. (113889)

5 Bioterrorism/or emergencies/or (bioterror $\$$ or emergency or emergent).tw. (146705)

64 or $5(257604)$

73 and 6 (17661)

8 Attitude/or attitude\$.tw. (98801)

9 Perception/or (perception\$ or perceive\$).tw. (174307)

10 communication barriers/or barrier\$.tw. (114683)

11 "Patient Acceptance of Health Care"/or (accept\$ or rejection or willingness).tw. (301968)

12 Motivation/or Intention/or (intention\$ or motivat\$).tw. (110507)

13 Health Knowledge, Attitudes, Practice/or "Attitude of Health Personnel"/(118620)

14 exp decision making/or (decision\$ adj1 making).tw. (122071)

15 or/8-14 (890811)

167 and $15(1182)$

17 animals/not humans/(3425576)

1816 not 17 (1100)

19 qualitative research/or qualitative.tw. (87357)

20 interview/or health surveys/or interviews as topic/or narration/or questionnaires/or Focus Groups/(299201)

21 (interview \$ or survey $\$$ or focus group \$ or questionnaire\$ or narrat\$ or experience\$).tw. (1039040)

22 Observation/or observation\$.tw. (469567)

23 or/19-22 (1613210)

2418 and 23 (392)

25 from 24 keep 1-392 (392)

\section{Database: EMBASE Classic plus} EMBASE 1947 to 2010 July 22

\section{Search strategy}

1 vaccination/or mass immunization/or vaccin\$.tw. (168265)

2 anthrax vaccine/or smallpox vaccine/or influenza vaccine/ or avian influenza vaccine/(19211)
3 (H1N1 or swine flu or H5N1 or avian flu or bird flu). tw. (6132)

4 or/1-3 (176731)

5 epidemic/or (pandemic\$ or epidemic\$ or outbreak\$). tw. (89724)

6 biological warfare/or (bioterror\$ or emergency or emergent).tw. (116221)

75 or $6(203711)$

84 and 7 (15798)

9 health personnel attitude/or nurse attitude/or physician attitude/or patient attitude/(48932)

10 attitude/or attitude\$.tw. (73587)

11 perception/or (perception\$ or perceive\$).tw. (142016)

12 barrier\$.tw. (97777)

13 (accept\$ or rejection or willingness).tw. (278073)

14 behavior/or motivation/(105523)

15 (intention\$ or motivat\$).tw. (71526)

16 decision making/or (decision\$ adj1 making).tw. (78039)

17 or/9-16 (782106)

18 qualitative research/or qualitative.tw. (73896)

19 exp interview/(60764)

20 health survey/(75971)

21 exp questionnaire/(164048)

22 information processing/(66875)

23 (interview\$ or survey\$ or focus group\$ or questionnaires\$ or narrat\$ or experience\$).tw. (850724)

24 observational study/or observation\$.tw. (489505)

25 or/18-24 (1509918)

268 and 17 and 25 (294)

27 from 26 keep 1-294 (294)

Database: PsycINFO ${ }^{\circledR} 1806$ to

July week 32010

Search strategy

1 immunization/or vaccin\$.tw. (2506)

2 (h1n1 or swine flu or h5n1 or avian flu or bird flu).tw. (99)

31 or $2(2583)$

4 epidemics/or (pandemic\$ or epidemic\$ or outbreak\$). tw. (7129)

5 Bioterrorism/or (bioterror\$ or emergency or emergent). tw. (18614)

64 or 5 (25567)

73 and 6 (291)

8 Health Personnel Attitudes/or Health Attitudes/or Attitudes/or attitude\$.tw. (166439)

9 Communication Barriers/or barrier\$.tw. (25197) 
10 Risk Perception/or Perception/or (perception\$ or perceive\$).tw. (265390)

11 (accept\$ or rejection or willingness).tw. (90606)

12 Consumer Behavior/or Client Attitudes/(23532)

13 Intention/or Motivation/or (intention\$ or motivat\$).tw. (123477)

14 decision making/or choice behavior/(41198)

15 (decision\$ adj1 making).tw. (44649)

16 or/8-14 (610471)

17 Qualitative Research/or qualitative.tw. (56552)

18 interviews/(5241)
19 Mail Surveys/or Consumer Surveys/or Telephone Surveys/or Surveys/(5346)

20 questionnaires/(11041)

21 (interview\$ or survey $\$$ or focus group\$ or questionnaire\$ or narrat\$ or experience\$).tw. (647996)

22 observation methods/or observation\$.tw. (90753)

23 or/17-22 (731033)

247 and 16 and 23 (34)

25 from 24 keep 1-34 (34)

\section{Publish your work in this journal}

Infection and Drug Resistance is an international, peer-reviewed openaccess journal that focuses on the optimal treatment of infection (bacterial, fungal and viral) and the development and institution of preventive strategies to minimize the development and spread of resistance. The journal is specifically concerned with the epidemiology of antibiotic resistance and the mechanisms of resistance development and diffusion in both hospitals and the community. The manuscript management system is completely online and includes a very quick and fair peerreview system, which is all easy to use. Visit http://www.dovepress.com/ testimonials.php to read real quotes from published authors. 